\title{
One- and Six-month Outcomes of Patients with Non-ST Elevation Myocardial Infarction
}

\author{
Hossein Vakili ${ }^{1}$, Roxana Sadeghi ${ }^{1,}{ }^{*}$, Neda Toofaninejad ${ }^{2}$, \\ Tooba Akbari ${ }^{2}$, Naser Kachoueian ${ }^{3}$
}

${ }^{1}$ Associate Professor of Interventional Cardiology, Cardiovascular Research Center, School of Medicine, Shahid Beheshti University of Medical Sciences, Tehran, Iran

${ }^{2}$ Cardiologist, Cardiovascular Research Center, School of Medicine, Shahid

Beheshti University of Medical Sciences, Tehran, Iran

${ }^{3}$ Cardiac surgeon, Cardiovascular Research Center, School of Medicine, Shahid

Beheshti University of Medical Sciences, Tehran, Iran

* Corresponding author: Roxana Sadeghi, Cardiovascular Research Center, Shahid Beheshti University of Medical Sciences, Tehran, Iran. Tel: +98-2122083106, Fax:

DOI: $10.21859 / \mathrm{ijcp}-010303$ +98-2122083106,E-mail: roxan.sadeghi@sbmu.ac.ir

\begin{tabular}{l} 
Submited: 09.10 .2016 \\
Accepted: 10.10 .2016 \\
\hline
\end{tabular}

Keywords:

Myocardial Infarction

Outcome

Mortality

Ejection Fraction

(C) 2016. International Journal of Cardiovascular Practice.

\begin{abstract}
Introduction: Use of risk scoring systems in patients with acute coronary syndrome helps with summarizing important prognostic data of the disease and facilitates calculating confidence limits and comparing survival rates between different treatments. In the present study, the researchers first aimed at assessing mid-term outcome of patients with non-ST elevation myocardial infarction (NSTEMI), and then determining main predictors of this outcome to improve definitive criteria for designing a risk scoring system in the population. Methods: In a prospective cohort study, 124 patients with NSTEMI, diagnosed according to ACC/AHA guidelines and hospitalized in an academic hospital in 2013, were consecutively assessed. Baseline characteristics were collected via interviewing, physical examination, and reviewing the recorded files. All the patients were followed for one and six months to assess mid-term outcomes regarding mortality and major adverse cardiac events (MACE). MACE is defined as the occurrence of at least one of the events of death, myocardial infarction, repeated revascularization, or re-hospitalization.

Results: One-month death occurred in 3.2\%, re-hospitalization in $4.0 \%$, and myocardial infarction in none of the patients. In addition, regarding the six-month outcomes status, mortality rate was determined in $6.4 \%$, re-hospitalization in $22.6 \%$, and myocardial infarction in $4.8 \%$ of patients. Hence, one- and six-month MACE rates were $7.3 \%$ and $27.4 \%$, respectively. Furthermore, three- and six-month survival rates were estimated to be $96.8 \%$ and $93.6 \%$, respectively. According to the Cox-proportion hazard modeling, only reduced left ventricular ejection fraction (LVEF) $(\mathrm{HR}=0.909, \mathrm{P}=0.017)$, history of chronic kidney injury $(\mathrm{HR}=8.884, \mathrm{P}=0.005)$, and Inotrope use $(\mathrm{HR}=35.759, \mathrm{P}=$ 0.012 ) could predict the six-month MACE. None of the other indexes including general coronary risk factors, echocardiography parameters, and level of cardiac enzymes could predict mortality rate.

Conclusions: Patients with NSTEMI may face high six-month MACE which can be predicted by low LVEF, history of renal injury and use of inotrope. Therefore, to define risk stratification system, these indicators should be considered as well.
\end{abstract}

\section{INTRODUCTION}

The ratio of non-ST elevation myocardial infarction (NSTEMI) to ST elevation myocardial infarction (STEMI) continues to increase, and now less than one-third of myocardial infarctions (MIs) are due to STEMI [1]. Recently, the wide use of more sensitive tests such as analyzing serial high-sensitivity cardiac troponin $\mathrm{T}$ (hs-cTnT), which can detect even small sizes of myocardial necrosis, has increase diagnostic accuracy and led to increasing incidence of NSTEMI instead of unstable angina [2-5]. Although there have been significant improvements in the care of patients with cardiovascular disease, cardiovascular death mainly by coronary heart disease remains the leading cause of mortality worldwide [1]. Risk scores are simple, applicable and more accurate tools at risk stratification, in which prognostic value of several independent risk factors on presentation are shown. Indexes that compound several related clinical variables of 
the same underlying pathophysiologic event are more powerful than any individual variable and could improve prognostic analysis in regression modeling techniques [6-8]. For instance, history of myocardial infarction, congestive heart failure, $\mathrm{Q}$ waves on electrocardiogram and high troponin $\mathrm{T}$ concentrations all represent different aspects of the extent of myocardial injury $[9,10]$. In addition to the extent of myocardial injury, the extent of coronary artery disease and its resistance to management are the main prognostic determinants of acute coronary syndrome [11].

Age, heart rate, systolic blood pressure, Killip class, ST segment deviation, resuscitation from cardiac arrest, elevated cardiac enzymes and serum creatinine concentration are powerful prognostic factors in GRACE and PURSUIT scoring systems [12-14].

Seven independent predictor variables have been identified as TIMI risk factors including age $>65$ years, three cardiovascular risk factors, known coronary artery disease (50\% stenosis), severe angina symptoms, use of aspirin in the last seven days, ST segment deviation $>0.05 \mathrm{mV}$, and elevated serum cardiac markers of necrosis $[15,16]$

Use of risk scoring systems in patients with acute coronary syndrome helps to summarize important prognostic data of the disease and facilitates comparing survival rate between different treatments $[17,18]$.

In the present study, we aimed to first assess mid-term outcome of patients with NSTEMI, and then determine main predictors of this outcome.

\section{METHODS}

In a prospective cohort study, 124 patients with diagnosed NSTEMI according to ACC/AHA guidelines, who were hospitalized at Modarres hospital between March 2012 and September 2013, were consecutively included. Baseline characteristics were collected via interviewing, physical examination, and reviewing the recorded files including demographic characteristics, medical history, medication, previous cardiac intervention, laboratory parameters, and functional class status.

Patients were also assessed using two-dimensional echocardiography to determine structural and functional parameters such as left ventricular ejection fraction, end systolic and diastolic diameters, and also diastolic functional indexes. They also underwent coronary angiography to determine presence and severity of coronary arteries involvement.

To assess mid-term outcomes of NSTEMI, all the patients were followed for one and six months to evaluate mid-term outcomes regarding mortality and major adverse cardiac events (MACE), defined as the occurrence of at least one of the events of myocardial infarction, repeated revascularization, or re-hospitalization.

Results were presented as mean \pm standard deviation (SD) for quantitative variables and were summarized by frequency (\%) for categorical variables. Continuous variables were compared using t-test or non-parametric Mann-Whitney U test, whenever the data did not appear to have normal distribution or when the assumption of equal variances was violated across the two study groups. Categorical variables were, on the other hand, compared using chi-squared test or Fisher's exact test when more than $20 \%$ of cells with expected count of less than five were observed. Cox proportional hazard model was used to determine main correlates of MACE. Statistical analysis was performed by SPSS version 21.0 (SPSS Inc., Chicago, IL). P values of 0.05 or less were considered statistically significant.

\section{RESULTS}

Totally, 124 patients were included in the study. The mean age of patients was $62.40 \pm 11.07$, ranging 35 to 93 years. Baseline demographic and clinical characteristics of patients are shown in Table 1 .

\begin{tabular}{|c|c|}
\hline Variables & Amount \\
\hline \multicolumn{2}{|l|}{ Demographics } \\
\hline Age (y) & $62.4 \pm 11.7$ \\
\hline $\operatorname{BMI}\left(\mathrm{k} / \mathrm{m}^{2}\right)$ & $26.28 \pm 2.95$ \\
\hline Male sex (\%) & 72.9 \\
\hline \multicolumn{2}{|l|}{ Medical History (\%) } \\
\hline Hypertension & 56.5 \\
\hline Diabetes mellitus & 33.9 \\
\hline Hyperlipidemia & 50.8 \\
\hline Obesity $\left(\mathrm{BMI}>30 \mathrm{~kg} / \mathrm{m}^{2}\right)$ & 29.8 \\
\hline Current smoking & 34.9 \\
\hline Prior $\mathrm{CABG}$ & 15.3 \\
\hline Prior PCI & 12.1 \\
\hline Peripheral arterial disease & 11.3 \\
\hline Prior heart failure & 27.4 \\
\hline Prior cerebrovascular events & 8.1 \\
\hline Prior renal failure & 12.1 \\
\hline Chronic lung disease & 15.3 \\
\hline Previous Aspirin use & 52.4 \\
\hline \multicolumn{2}{|l|}{ Recent Function Class } \\
\hline I & 38.7 \\
\hline II & 44.4 \\
\hline III & 16.1 \\
\hline IV & 0.8 \\
\hline \multicolumn{2}{|l|}{ Presentation Features } \\
\hline Typical chest pain (\%) & 65.3 \\
\hline Chest pain + Dyspnea (\%) & 33.1 \\
\hline Atypical chest pain (\%) & 1.6 \\
\hline Initial heart rate (beats/min) & $85.02 \pm 1.49$ \\
\hline Initial systolic BP $(\mathrm{mm} \mathrm{Hg})$ & $130.85 \pm 26.22$ \\
\hline \multicolumn{2}{|l|}{ ECG Findings (\%) } \\
\hline Pathologic Qwave & 7.0 \\
\hline ST depression & 68.5 \\
\hline Transient ST elevation & 4.0 \\
\hline \multicolumn{2}{|l|}{ Laboratory Results } \\
\hline Peak Troponin $(\mu \mathrm{g} / \mathrm{l})$ & $3.08 \pm 2.48$ \\
\hline Peak CPK (IU/L) & $631 \pm 5.00$ \\
\hline Peak CK.MB (IU/L) & $87.06 \pm 6.83$ \\
\hline Hemoglobin $(\mathrm{g} / \mathrm{dL})$ & $14.07 \pm 1.68$ \\
\hline Serum creatinine $(\mathrm{mg} / \mathrm{dL})$ & $1.25 \pm 0.32$ \\
\hline \multicolumn{2}{|l|}{ TIMI Risk Score (\%) } \\
\hline Low risk (score $0-2$ ) & 6.5 \\
\hline Intermediate risk (score 3-4) & 56.5 \\
\hline High risk (5-7) & 37.1 \\
\hline
\end{tabular}

Values are presented as percentages or mean \pm SD.

$\mathrm{BP}$ : Blood pressure; BMI: Body mass index; CABG: Coronary artery bypass grafting; ECG: Electrocardiogram; TIMI: Thrombolysis in Myocardial Infarction; PCI: Percutaneous coronary intervention. 
The most common traditional cardiovascular risk factors were hypertension (56.5\%), followed by hyperlipidemia, current smoking, diabetes mellitus, and obesity. Nearly one third of patient (27.8\%) had history of coronary revascularization, percutaneous coronary intervention (PCI) or coronary artery bypass grafting (CABG); about half had history of previous aspirin administration. Medical treatments during hospitalization, echocardiography and angiography findings are demonstrated in Table 2 . Only a few patients $(0.8 \%)$ received low molecular weight heparin instead of unfractionated heparin.

Approximately $96 \%$ of the patients underwent cardiac catheterization $(37.1 \%$ within 24 hours from index admission and $58.1 \%$ after 24 hours), whereas $62.2 \%$ experienced percutaneous coronary intervention, $15.3 \%$ endured bypass surgery, and $22.5 \%$ were treated conservatively.

Based on the angiography report, three coronary vessel involvements were the most frequent results, followed by two vessel diseases (VD), one VD and left main disease (Table 2). Regarding the one-month outcomes, one-month death occurred in $3.2 \%$, re-hospitalization in $4.0 \%$, CABG in $0.8 \%$, and myocardial infarction in none of the patients. In addition, regarding the six-month outcomes, mortality rate was determined in $6.4 \%$, re-hospitalization in $22.6 \%$, CABG in $3.2 \%$, and myocardial infarction in $4.8 \%$ of patients. Hence, one- and six-month MACE rates were $7.3 \%$ and $27.4 \%$, respectively; survival rates at one and six months were $96.8 \%$ and $93.6 \%$, respectively.

According to univariate analysis, different variants predict six-month MACE (Table 3); however, based on the Cox-proportion hazard modeling, only reduced left ventricular ejection fraction $(\mathrm{LVEF})(\mathrm{HR}=0.909, \mathrm{P}=0.017)$, history of chronic kidney injury $(\mathrm{HR}=8.884, \mathrm{P}=0.005)$, and Inotrope usage $(\mathrm{HR}=35.759, \mathrm{P}=0.012)$ could predict six-month MACE.

In this context, none of the indexes including general coronary risk factors, echocardiography parameters, and level of cardiac enzymes could predict mortality rate.

\section{DISCUSSION}

According to the increasing trend of the overall incidence of NSTEMI compared with other components of acute coronary syndrome, the assessment of this ischemic event and also determining its related determinants are necessary. Besides, designing a risk stratification system to determine the level of risk in patients with NSTEMI can lead to better clinical management of these patients and also to schedule appropriate treatment programs for these patients.

In the present study, we first attempted to determine midterm outcomes of patients with NSTEMI and then aimed to assess main predictors of NSTEMI outcomes in the study population. Based on observation, the mean age of patients NSTEMI was $62.40 \pm 11.07$ years, consistent with those of Korea Acute Myocardial Infarction Registry (KAMIR) (63.6 \pm 12.2 years) [19]; but, they were younger than patients with NSTEMI in Malopolska Registry of Acute Coronary Syndromes performed by Dziewierz et al. (70.2 \pm 11.6 years) [20]. The most frequent cardiovascular risk factor was hypertension, consistent with most NSTEMI studies [19-21]; however, smoking and hyperlipidemia were more common in a cohort study [22].
In this study, the mid-term mortality rate in patients with NSTEMI was $6.4 \%$. Furthermore, one- and six-month MACE rates were $7.3 \%$ and $27.4 \%$, respectively. On the other hand, although patients with NSTEMI had an acceptable mortality rate, they experienced a high mid-term MACE rate; among every four patients, one faced with cardiac morbidities in a mid-term period.

In one report, 458 patients without persistent ST segment elevation acute coronary syndrome were assigned to early invasive strategy. Hospital and overall mortality rates were $3.3 \%$ and $4.8 \%$; respectively. MACE was observed in $20.3 \%$ of patients within six months [23].

Moreover, for the patient who had been referred for catheterization and the ones who underwent conservative strategy, Khalill et al. reported one-year mortality rate of $4 \%$ and $10 \%$; respectively [24]. In another study performed by Park HW et al., the MACE rates for early term (one month) and late-term (one year) were $6.9 \%$ and $8.0 \%$; respectively [25].

Table 2: In Hospital Medication, Echocardiography and Angiography Findings in Patients with Non-ST Elevation Myocardial Infarction

\begin{tabular}{|c|c|}
\hline Variables & Amounts \\
\hline \multicolumn{2}{|l|}{ Hospital Medication (\%) } \\
\hline UFH & 99.2 \\
\hline LMWH & 0.8 \\
\hline Aspirin + clopidegrol & 67.7 \\
\hline Aspirin + clopidegrol + eptifibatide & 32.3 \\
\hline Inotrope & 5.6 \\
\hline Statin & 100 \\
\hline Beta blockers & 89.5 \\
\hline Calcium blockers & 2.4 \\
\hline \multicolumn{2}{|l|}{ Echocardiography Parameters } \\
\hline LVEF (\%) & $43.61 \pm 11.35$ \\
\hline $\operatorname{LVEDD}(\mathrm{cm})$ & $5.34 \pm 0.64$ \\
\hline RVEDD (cm) & $3.05 \pm 0.28$ \\
\hline $\mathrm{Ea} / \mathrm{Ee}$ & $12.44 \pm 4.40$ \\
\hline TAPSE $(\mathrm{cm})$ & $1.89 \pm 0.27$ \\
\hline \multicolumn{2}{|l|}{$\operatorname{MR}(\%)$} \\
\hline Mild & 39.5 \\
\hline Moderate & 19.4 \\
\hline Severe & 2.4 \\
\hline \multicolumn{2}{|l|}{ Angiography Results (\%) } \\
\hline SVD & 12.9 \\
\hline $2 \mathrm{VD}$ & 29.8 \\
\hline $3 \mathrm{VD}$ & 33.9 \\
\hline LMD & 6.5 \\
\hline
\end{tabular}

Values are presented as percentages or mean \pm SD.

LMD: Left main disease; LMWH: Low-molecular-weight heparin; LVEF: Left ventricular ejection fraction; LVEDD: Left ventricular end diastolic diameter; MR: Mitral regurgitation; RVEDD: Right ventricular end diastolic diameter; SVD: Single vessel disease; 2VD: Two vessel disease; 3VD: Three vessel disease; TAPSE: Tricuspid annular plane systolic excursion; UFH: Unfractionated heparin. 


\begin{tabular}{|c|c|c|c|}
\hline Characteristics & $\operatorname{MACE}(+),(n=34)$ & $\operatorname{MACE}(-),(\mathbf{n}=90)$ & Pvalue \\
\hline Male gender & $27(79.4)$ & $63(70)$ & 0.295 \\
\hline Age (y) & $66.41 \pm 10.64$ & $60.88 \pm 10.90$ & 0.013 \\
\hline BMI (kg/m2) & $25.56 \pm 2.31$ & $26.55 \pm 3.13$ & 0.097 \\
\hline Hypertension & $23(67.6)$ & $43(47.8)$ & 0.122 \\
\hline Diabetes mellitus & $12(35.3)$ & $30(33.3)$ & 0.837 \\
\hline Current Smoking & $16(47.1)$ & $27(30.0)$ & 0.032 \\
\hline Hyperlipidemia & $16(47.1)$ & $47(52.2)$ & 0.608 \\
\hline Prior CABG & $9(26.5)$ & $17(18.9)$ & 0.019 \\
\hline Prior PCI & $4(11.8)$ & $11(12.2)$ & 0.889 \\
\hline Prior heart failure & $19(55.9)$ & $15(16.0)$ & $<0.001$ \\
\hline Prior renal failure & $9(26.5)$ & $6(6.7)$ & 0.003 \\
\hline Prior cerebrovascular events & $3(8.8)$ & $7(7.8)$ & 0.849 \\
\hline Peripheral arterial disease & $6(17.6)$ & $8(8.9)$ & 0.169 \\
\hline Opium & $7(20.6)$ & $7(7.8)$ & 0.132 \\
\hline LVEF & $34.44 \pm 13.30$ & $47.08 \pm 8.61$ & $<0.001$ \\
\hline LVEDD & $5.77 \pm 0.78$ & $5.18 \pm 0.49$ & $<0.001$ \\
\hline RVEDD & $3.12 \pm 0.31$ & $3.03 \pm 0.26$ & 0.066 \\
\hline TAPSE & $1.7 \pm 0.3$ & $1.93 \pm 0.2$ & 0.005 \\
\hline $\mathbf{E a} / \mathbf{E e}$ & $13.7 \pm 4.7$ & $11.9 \pm 4.3$ & 0.060 \\
\hline \multicolumn{4}{|l|}{ MR } \\
\hline Mild & $12(35.3)$ & $37(41.1)$ & 0.149 \\
\hline Moderate & $14(41.2)$ & $10(11.1)$ & 0.001 \\
\hline Severe & $1(2.9)$ & $2(2.2)$ & 0.889 \\
\hline TIMI Score & $4.7 \pm 1.2$ & $3.9 \pm 1.2$ & 0.001 \\
\hline ACC/AHA high risk & $21(63.6)$ & $26(28.5)$ & 0.001 \\
\hline ACC/AHA moderate risk & $11(33.3)$ & $58(63.7)$ & 0.004 \\
\hline ACC/AHA low risk & $1(3.0)$ & $7(7.6)$ & 0.32 \\
\hline Previous Aspirin usage & $20(60)$ & $45(49)$ & 0.185 \\
\hline \multicolumn{4}{|l|}{ Drugs in hospitalization } \\
\hline Aspirin + Clopidegrol & $27(79.4)$ & $57(63.3)$ & 0.251 \\
\hline Aspirin + Clopidegrol + Eptifibatide & $7(20.6)$ & $33(36.7)$ & 0.095 \\
\hline $\mathrm{UFH}$ & $34(100)$ & $89(98.9)$ & 0.537 \\
\hline Inotrope & $6(17.6)$ & $1(1.1)$ & 0.002 \\
\hline Beta blockers & $24(70.6)$ & $87(96.7)$ & 0.226 \\
\hline Pathologic Qwave & $4(11.8)$ & 0 & 0.005 \\
\hline ST-T change & $27(79.4)$ & $58(64.4)$ & 0.001 \\
\hline Angiography within $24 \mathrm{~h}$ & $7(21.2)$ & $39(43.3)$ & 0.035 \\
\hline \multicolumn{4}{|l|}{ Angiography results } \\
\hline SVD & $1(3.1)$ & $15(17.2)$ & 0.005 \\
\hline $2 \mathrm{VD}$ & $7(20.6)$ & $30(34.5)$ & 0.021 \\
\hline $3 \mathrm{VD}$ & $15(46.9)$ & $27(31.0)$ & 0.001 \\
\hline LMD & $3(9.4)$ & $5(5.7)$ & 0.445 \\
\hline
\end{tabular}

Values are presented as $\mathrm{n}(\%)$ or mean \pm SD.

Abbreviations are as in Tables 1 and 2. MACE: Major adverse cardiac events.

From the CRUSADE registry, one-year mortality rate in older patients with NSTEMI (aged $\geq 65$ years) was $24.4 \%$, and age was the most significant predictor of mortality [21]. Recently, Kim et al. reported a six-months MACE ranging from $12.4 \%$ to $23.1 \%$ based on TIMI risk score for low- to high-risk patients with NSTEMI, respectively, in KAMIR [19].

In the second step of study, we found that patients with MACE were older and more likely to be current smokers, have a history of $\mathrm{CHF}$, CABG, CKD, pathologic Q wave, ST-segment changes, $\mathrm{LV}$ and RV dysfunction, moderate $\mathrm{MR}$, catheterization after 24 hours, and inotrope usage during hospitalization; however, the correlation of severe MR and MACE was not statistically significant, which may be due to insufficient total number of severe MRs. The TIMI risk score (TRS) system 
had a good correlation with MACE for patients in the highrisk group. By Cox-proportion hazard analysis, we could introduce reduced LVEF, history of chronic kidney injury, and Inotrope use as major factors triggering mid-term MACE in patients with NSTEMI.

In KAMIR by Kim et al., Killip class above III, the presence of heart failure or cardiogenic shock and NT-ProBNP demonstrated good correlations with MACE, and the TRS system had a good correlation with MACE for patients in the low and intermediate groups [19].

On the other hand, demographic parameters, echocardiography indexes and also increased level of cardiac enzymes were not correlated with poor mid-term outcome in those patients.

It seems that the type of predictors of NSTEMI consequences can be different in various populations depending on characteristics of population, diagnostic criteria of MACE, follow-up time, and number of patients included.

This study revealed that in a limited portion of the Iranian population, only three factors including reduced LVEF, history of chronic kidney injury, and Inotrope usage could predict six-month MACE, suggesting that the abovementioned parameters are probably more significant than other prognostic factors reported.

Limitations of this study can be discussed from various points. First, a small number of participants was used; thus, the findings should be treated with care. Second, other variables could provide novel prognostic results. Third, further studies need to be accomplished to achieve verification of new scoring systems.

In conclusion, patients with NSTEMI may face high sixmonth MACE, which can be predicted by low LVEF, history of renal injury, and use of inotrope.

Therefore, defining a risk stratification system should be considered in these patients.

\section{ACKNOWLEDGEMENTS}

This study was supported by Shahid Beheshti University of Medical Sciences and was extracted from the doctorate dissertation of Dr. N. Toofani Nejad.

\section{CONFLICTS OF INTEREST}

There is no conflict of interest for the present study.

\section{REFERENCES}

1. Roger VL, Go AS, Lloyd-Jones DM, Benjamin EJ, Berry JD, Borden WB, et al. Heart disease and stroke statistics--2012 update: a report from the American Heart Association. Circulation. 2012;125(1):e2e220. DOI: 10.1161/CIR.0b013e31823ac046 PMID: 22179539

2. Giugliano RP, Braunwald E. The year in non-ST-segment elevation acute coronary syndrome. J Am Coll Cardiol. 2012;60(21):2127-39. DOI: $10.1016 /$ j.jacc.2012.08.972 PMID: 23103037

3. Rosamond WD, Chambless LE, Heiss G, Mosley TH, Coresh J, Whitsel E, et al. Twenty-two-year trends in incidence of myocardial infarction, coronary heart disease mortality, and case fatality in 4 US communities, 1987-2008. Circulation. 2012;125(15):184857. DOI: 10.1161/CIRCULATIONAHA.111.047480 PMID: 22420957

4. Nedkoff LJ, Briffa TG, Preen DB, Sanfilippo FM, Hung J, Ridout SC, et al. Age- and sex-specific trends in the incidence of hospitalized acute coronary syndromes in Western Australia. Circ Cardiovasc Qual Outcomes. 2011;4(5):557-64. DOI: 10.1161/CIRCOUTCOMES.110.960005 PMID: 21862718
5. Lee DC, Sui X, Artero EG, Lee IM, Church TS, McAuley PA, et al. Long-term effects of changes in cardiorespiratory fitness and body mass index on all-cause and cardiovascular disease mortality in men: the Aerobics Center Longitudinal Study. Circulation. 2011;124(23):2483-90. DOI: 10.1161/CIRCULATIONAHA.111.038422 PMID: 22144631

6. Bugiardini R. Risk stratification in acute coronary syndrome: focus on unstable angina/non-ST segment elevation myocardial infarction. Heart. 2004;90(7):729-31. DOI: 10.1136/hrt.2004.034546 PMID: 15201236

7. White HD. Pathobiology of troponin elevations: do elevations occur with myocardial ischemia as well as necrosis? J Am Coll Cardiol. 2011;57(24):2406-8. DOI: 10.1016/j.jacc.2011.01.029 PMID: 21658560

8. Turer AT, Addo TA, Martin JL, Sabatine MS, Lewis GD, Gerszten RE, et al. Myocardial ischemia induced by rapid atrial pacing causes troponin $\mathrm{T}$ release detectable by a highly sensitive assay: insights from a coronary sinus sampling study. J Am Coll Cardiol. 2011;57(24):2398-405. DOI: 10.1016/i.jacc.2010.11.066 PMID: 21658559

9. Reiter M, Twerenbold R, Reichlin T, Benz B, Haaf P, Meissner J, et al. Early diagnosis of acute myocardial infarction in patients with pre-existing coronary artery disease using more sensitive cardiac troponin assays. Eur Heart J. 2012;33(8):988-97. DOI: 10.1093/ eurheartj/ehr376 PMID: 22044927

10. de Lemos JA, Morrow DA, deFilippi CR. Highly sensitive troponin assays and the cardiology community: a love/hate relationship? Clin Chem. 2011;57(6):826-9. DOI: 10.1373/clinchem.2011.163758 PMID: 21471249

11. Body R, Carley S, McDowell G, Jaffe AS, France M, Cruickshank $\mathrm{K}$, et al. Rapid exclusion of acute myocardial infarction in patients with undetectable troponin using a high-sensitivity assay. J Am Coll Cardiol. 2011;58(13):1332-9. DOI: 10.1016/j.jacc.2011.06.026 PMID: 21920261

12. Granger CB, Goldberg RJ, Dabbous O, Pieper KS, Eagle KA, Cannon $\mathrm{CP}$, et al. Predictors of hospital mortality in the global registry of acute coronary events. Arch Intern Med. 2003;163(19):2345-53. DOI: $10.1001 /$ archinte.163.19.2345 PMID: 14581255

13. Keller T, Zeller T, Ojeda F, Tzikas S, Lillpopp L, Sinning C, et al. Serial changes in highly sensitive troponin I assay and early diagnosis of myocardial infarction. JAMA. 2011;306(24):2684-93. DOI: 10.1001/jama.2011.1896 PMID: 22203537

14. Antman EM, Cohen M, Bernink PJ, McCabe CH, Horacek T, Papuchis G, et al. The TIMI risk score for unstable angina/non-ST elevation MI: A method for prognostication and therapeutic decision making. JAMA. 2000;284(7):835-42. PMID: 10938172

15. Bonaca MP, Wiviott SD, Braunwald E, Murphy SA, Ruff CT, Antman EM, et al. American College of Cardiology/American Heart Association/European Society of Cardiology/World Heart Federation universal definition of myocardial infarction classification system and the risk of cardiovascular death: observations from the TRITON-TIMI 38 trial (Trial to Assess Improvement in Therapeutic Outcomes by Optimizing Platelet Inhibition With Prasugrel-Thrombolysis in Myocardial Infarction 38). Circulation. 2012;125(4):57783. DOI: 10.1161/CIRCULATIONAHA.111.041160 PMID: 22199016

16. Damman P, Wallentin L, Fox KA, Windhausen F, Hirsch A, Clayton $\mathrm{T}$, et al. Long-term cardiovascular mortality after procedure-related or spontaneous myocardial infarction in patients with non-ST-segment elevation acute coronary syndrome: a collaborative analysis of individual patient data from the FRISC II, ICTUS, and RITA-3 trials (FIR). Circulation. 2012;125(4):568-76. DOI: 10.1161/CIRCULATIONAHA.111.061663 PMID: 22199015

17. Fernandez-Berges D, Bertomeu-Gonzalez V, Sanchez PL, Cruz-Fernandez JM, Arroyo R, Barriales Alvarez V, et al. Clinical scores and patient risk stratification in non-ST elevation acute coronary syndrome. Int J Cardiol. 2011;146(2):219-24. DOI: 10.1016/j.ijcard.2010.04.016 PMID: 20439123

18. Braunwald E, Antman EM, Beasley JW, Califf RM, Cheitlin MD, Hochman JS, et al. ACC/AHA guideline update for the management of patients with unstable angina and non-ST-segment elevation myocardial infarction--2002: summary article: a report of the American College of Cardiology/American Heart Association Task Force on Practice Guidelines (Committee on the Management of Patients With Unstable Angina). Circulation. 2002;106(14):1893-900. PMID: 12356647 
19. Kim JH, Jeong MH, Ahn Y, Kim YJ, Chae SC, Seong IW, et al. A Novel Risk Stratification Model for Patients with Non-ST Elevation Myocardial Infarction in the Korea Acute Myocardial Infarction Registry (KAMIR): Limitation of the TIMI Risk Scoring System. Chonnam Med J. 2011;47(1):20-6. DOI: $10.4068 / \mathrm{cmj} .2011 .47 .1 .20$ PMID: 22111052

20. Dziewierz A, Siudak Z, Dykla D, Rakowski T, Mielecki W, Dubiel JS, et al. Management and mortality in patients with non-ST-segment elevation vs. ST-segment elevation myocardial infarction. Data from the Malopolska Registry of Acute Coronary Syndromes. Kardiol Pol. 2009;67(2):115-20; discussion 21-2. PMID: 19288373

21. Roe MT, Chen AY, Thomas L, Wang TY, Alexander KP, Hammill BG, et al. Predicting long-term mortality in older patients after non-STsegment elevation myocardial infarction: the CRUSADE long-term mortality model and risk score. Am Heart J. 2011;162(5):875-83 e1. DOI: 10.1016/j.ahj.2011.08.010 PMID: 22093204

22. Terkelsen CJ, Lassen JF, Norgaard BL, Gerdes JC, Jensen T, Got- zsche LB, et al. Mortality rates in patients with ST-elevation vs non-ST-elevation acute myocardial infarction: observations from an unselected cohort. Eur Heart J. 2005;26(1):18-26. DOI: 10.1093/ eurheartj/ehi002 PMID: 15615795

23. Szygula-Jurkiewicz B, Wilczek K, Zembala M, Mercik G, Polonski L. [Six-month outcomes and prediction of mortality in 458 patients with acute coronary syndromes without persistent ST segment elevation assigned to early invasive strategy]. Pol Arch Med Wewn. 2004;112(6):1459-66. PMID: 15962611

24. Khalill R, Han L, Jing C, Quan H. The use of risk scores for stratification of non-ST elevation acute coronary syndrome patients. Exp Clin Cardiol. 2009;14(2):e25-30. PMID: 19675816

25. Park HW, Yoon CH, Kang SH, Choi DJ, Kim HS, Cho MC, et al. Early- and late-term clinical outcome and their predictors in patients with ST-segment elevation myocardial infarction and non-ST-segment elevation myocardial infarction. Int J Cardiol. 2013;169(4):254-61. DOI: $10.1016 /$ j.ijcard.2013.08.132 PMID: 24071385 